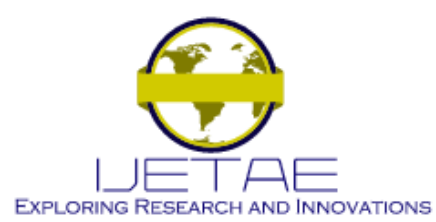

International Journal of Emerging Technology and Advanced Engineering

Website: www.ijetae.com (ISSN 2250-2459, ISO 9001:2008 Certified Journal, Volume 10, Issue 08, August 2020)

\title{
Exergetic Modeling of an IGCC Plant
}

\author{
Agberegha, Orobome Larry ${ }^{1}$, Edefeadhe Godspower ${ }^{2}$ \\ ${ }^{I}$ Department of Mechanical Engineering, Federal University of Petroleum Resources, Effurun, Delta State. \\ ${ }^{2}$ Department of Mechanical Engineering, Delta State Polytechnic, Otefe-Oghara, Delta State.
}

\begin{abstract}
Thermal power plants covert fuel into electricity, heat and even cooling of buildings and devices. These fuels are numerous: coal, natural gas, petroleum products, domestic and industrial wastes, landfill gas, biogas, biomass, agricultural waste. Integrated Gasification Combined Cycle (IGCC) is considered as a viable option for low emission power generation and carbon-dioxide sequestration. The integrated gasification combined cycle (IGCC) is an electrical power generation system which offers efficient generation from coal with lower effect on the environment than conventional coal power plants. An Integrated Gasification Combined Cycle (IGCC) is a promising green technology applied for thermal power plants. It offers an efficient way to generate electricity from coal, biomass or any other suitable solid or liquid fuels with lower impact to the environment. The biggest challenge of making IGCC to become a viable technology is its high energy production cost. An IGCC plant is a complex process system which involves processing units operated in very extreme conditions. Integrated Gasification Combined Cycle (IGCC) is one of the most promising technologies for power generation; the environmental benefits and the higher energy conversion efficiency distinguish it from traditional coal generation technologies. IGCC performance is affected by different technological and operational aspects, e.g. gasification technologies, gasifier agent, coal rank, environmental conditions, and power demand. However, further improvement of its efficiency and thereby lowering emissions are important tasks to achieve a more sustainable energy production. This work was carried out to identify and quantify the sources of inefficiencies in an Integrated Gasification Combined Cycle (IGCC) plant. Results show that the highest exergy destruction took place in the combustion chamber and the HRSG. .
\end{abstract}

\section{INTRODUCTION}

Meeting the challenge of delivering clean, affordable, and secure electric power is critical to sustaining the growth and prosperity of human society. With continued focus on the use of cheap and abundant coal resources for electric power generation, this compound energy challenge shifts to that of reducing greenhouse gas emissions, most importantly carbon dioxide (CO2) (Bhattacharyya et. al., 2011). Coal-fired power stations contribute about $20 \%$ of the worldwide $\mathrm{CO} 2$ emissions arising from the utilization of fossil fuels (Wang, 2016).
The gas turbine combined cycle (GTCC) is an advanced power generation system but it cannot accept coal as a fuel directly, until integrated gasification combined cycle (IGCC) technology was developed to combine the clean coal technology and combined cycle system together. The IGCC power plant, with high specific power, high efficiency and low emissions, is one of the best solutions for coal burning power generation (Huang et. al., 2016). Clean coal technologies have an increasing trend and utilize coal very efficiently without harmful effects. The most promising technology for effective and harmless utilization of coal is gasification. An integrated gasification combined cycle (IGCC) uses coal to produce hydrogen and $\mathrm{CO}$ in a gasifier, and combustion takes place in the combustion chamber of a gas turbine. It has advantages and disadvantages when compared to other alternatives. The net efficiency of an IGCC is larger compared to a conventional thermal power plant and less than a natural gas fired combined cycle. It depends on the gasification and gas cleaning technology. Gasifier type, oxidant type, coal feeding system, and gas cleaning system selections directly affect the performance of the overall power plant. (Amirabedin, et. al., 2013)

Integrated Gasification Combined Cycle (IGCC) is considered as a viable option for low emission power generation and carbon-dioxide sequestration. Modelling development and simulation study is essential part for the process of IGCC design and development. (Wang, 2013). The integrated gasification combined cycle (IGCC) is an electrical power generation system which offers efficient generation from coal with lower effect on the environment than conventional coal power plants. However, further improvement of its efficiency and thereby lowering emissions are important tasks to achieve a more sustainable energy production (Jiménez et. al., 2009). An Integrated Gasification Combined Cycle (IGCC) is a promising green technology applied for thermal power plants. It offers an efficient way to generate electricity from coal, biomass or any other suitable solid or liquid fuels with lower impact to the environment. The biggest challenge of making IGCC to become a viable technology is its high energy production cost. 


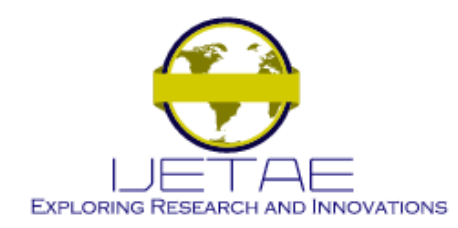

\section{International Journal of Emerging Technology and Advanced Engineering Website: www.ijetae.com (ISSN 2250-2459, ISO 9001:2008 Certified Journal, Volume 10, Issue 08, August 2020)}

This creates a barrier for this green technology to enter into the stage of a highly competitive electricity market. An IGCC plant is a complex process system which involves processing units operated in very extreme conditions. Proper material and energy integration may provide a hope for cost reduction (Wang et. al., 2013). Integrated Gasification Combined Cycle (IGCC) is one of the most promising technologies for power generation; the environmental benefits and the higher energy conversion efficiency distinguish it from traditional coal generation technologies. IGCC performance is affected by different technological and operational aspects, e.g. gasification technologies, gasifier agent, coal rank, environmental conditions, and power demand. This group of conditions hinders the assessment process and conduces necessarily to the use of thermodynamic simulation tools (Nieto et. al., 2008). The integrated gasification combined cycle (IGCC) is a power generation technology which combines clean coal technology with a combined cycle. The system modeling is significant for design, operation and maintenance of the IGCC power plant. However, the previous IGCC modeling methods only contained a simplified compartment gasifier model, which is useful to consider the heat transfer and chemical reaction inside the gasifier, but cannot analyze the pressure and flow distribution (Huang et. al., 2016). Integrated gasification combined cycle (IGCC) plants are a promising technology option for power generation with carbon dioxide $(\mathrm{CO} 2)$ capture in view of their efficiency and environmental advantages over conventional coal utilization technologies (Bhattacharyya et. al., 2011). The current studies on power plant technologies suggest that Integrated Gasification Combined Cycle (IGCC) systems are an effective and economic $\mathrm{CO} 2$ capture technology pathway. In addition, the system in conventional configuration has the advantage of being more "CO2 capture ready" than other technologies. Pulverized coal boilers (PC) have, however, proven high technical performance attributes and are economically often most practical technologies (Huang, et. al., 2010).

(Wang, 2013) carried out Modelling and Simulation Study of IGCC Power Plant with Activated Carbon-based arbon Capture Process. In this work, modelling and simulation study of IGCC power plant by building submodules such as gasifier, water gas shift reactor, acid gas removal unit, gas turbine and HRSG, etc. and connecting these modules together for the whole process study is carried out.
In addition, the impact for the integration of IGCC with activated carbons-based pressure swing adsorption carbon capture process is investigated by using a PSA model developed and validated by University of Birmingham. A simplified zero dimension gasification model is developed based on Texaco gasifier and validated by reference and industry data. The model development is based on mass balance, chemical equilibrium and energy balance. The prediction results for syngas contents concentrations are proved to be reasonably acceptable and the syngas contents changes with key input parameters changes are studied. The model is then used to generate a variable syngas stream to study the dynamic performance of the other submodules. A one dimension dynamic model based on Shell slagging gasifier is developed. The model can successfully show the characteristics of slag layers formation and the syngas stream change with response to input parameters change. By using step rise of oxygen input and steam blast input, the dynamic performance of syngas temperature, syngas contents, slag mass flow rate and slag layers thickness is analysed and compared. It is found that oxygen input show relative larger impact on gasifier operation than steam blast for the studied working conditions. Auxiliary modules in a gasification enabled plant and combined cycle power plant are modelled with Thermolib Software. Basic principles of this software are introduced. Simplified quench process, WGS with heat recovery, acid gas removal unit, gas turbine, HRSG and electrical generator are modelled by using the blocks from Thermolib. The simulation results show the dynamic changes of key output variables such as power output, syngas temperature and contents concentrations. PSA model developed by UoB based on ACs is introduced and a 9 step 8 beds cycle model is used for the integration with IGCC model. This PSA model can achieve $80.89 \% \mathrm{CO} 2$ capture rate with $87.33 \%$ of $\mathrm{N} 2$ recovery rate without any additional equipment. N2 is used to represent $\mathrm{H} 2$ for the simulation. Four cases for IGCC integrated with carbon capture are studied for the energy penalty analysis. It is predicted that the efficiency loss for IGCC power plant with $80.89 \%$ carbon capture will be $10.96 \%$. The limitations of using $\mathrm{N} 2$ to represent $\mathrm{H} 2$ for the PSA model are discussed and it is predicted the real efficiency loss will be lower than the simulation results.

(Amirabedin et. al., 2013) carried out Exergetic evaluation of an integrated gasification combined cycle power plant simulated by seven different types of Turkish lignite. 


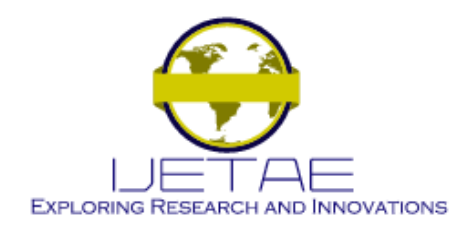

\section{International Journal of Emerging Technology and Advanced Engineering}

Website: www.ijetae.com (ISSN 2250-2459, ISO 9001:2008 Certified Journal, Volume 10, Issue 08, August 2020)

In this study, exergy analysis of an integrated gasification combined cycle (IGCC) operating with 7 different types of low rank Turkish lignite was performed. The purpose was to determine and compare the performance of each type of lignite in the same gasifier. Exergy destruction of each component and exergetic performance of the overall plant was also investigated. In addition, $\mathrm{CO} 2$ emissions of each type of lignite were calculated. The results showed that Yenik"oy lignite had the best performance among the different types of lignite, with 491 MW net power and $37.88 \%$ net exergy efficiency (without acid gas). It also had the minimum amount of $\mathrm{CO} 2$ emission at $726 \mathrm{~kg} / \mathrm{MWh}$. Therefore, Yenik"oy lignite was chosen as a case study fuel and a detailed exergy analysis of its components was applied. The results showed that the major exergy destructions took place in the gasifier and the combustion chamber at $46.15 \%$ and $22.74 \%$, respectively.

(Wang et. al., 2015) investigated simultaneous Integration and Optimization of an IGCC Plant. In this paper, a mathematical model of an IGCC plant was built that includes a gasification unit, an Air Separation Unit (ASU) and a Combined Cycle unit. A modified Gibbs free energy model is used for predicting the composition of the syngas taking into account material and energy balances. The proposed gasification model results in syngas composition similar to the experimental data provided in literature. What's more, Combined Cycle unit is simulated with isentropic assumption plus efficiency. While ASU is simulated mainly using the rigorous distillation model. Although individual processing unit optimization plays a significant role in enhancing the plant performance, an optimal integration among the three units still has significant potential to improve the efficiency, availability, and operability of a coal-fed IGCC power plant. The proposed mathematical model allows material and energy integration to be performed within and among different processing units while optimizing the IGCC plant as a whole. Different material and energy integration schemes were considered with respect to the overall thermal efficiency of the IGCC plant. The good performance is shown by about $2 \%$ overall efficiency increment in the case study.

(Nieto et. al., 2008) presented Simulation Of Igcc Technologies: Influence Of Operational Conditions (Environmental And Fuel Gas Production). In this work thermodynamics analysis simulations were conduced in Hysys and GateCycle. Simulations in Hysys were carried out for different gasification technologies, kinetic reactions, gasifying agents and coal types.
Syngas composition and lower heat values were calculated for the all different conditions and had been loaded into GateCycle in which Combined Cycle efficiency were studied for different environmental conditions. Results show behavior for IGCC technologies at different places according to its environmental and operational conditions, and coal rank.

(Huang et. al., 2016) Modeling and Simulation of IGCC Considering Pressure and Flow Distribution of Gasifier. In order to obtain a more accurate model of IGCC system, the volume-resistance technique and modular modeling method are utilized in this paper. The new model can depict the dynamic response and distribution characteristics of the gasifier, as well as their influence on the IGCC system. The simulation result of the gasifier and IGCC system shows an obvious delay after considering pressure and flow distribution. Therefore, the proposed IGCC system model can obtain a more reliable result when considering the distribution characteristics of the gasifier.

(Bhattacharyya et. al., 2011) presented Steady-State Simulation and Optimization of an Integrated Gasification Combined Cycle Power Plant with CO2 Capture. This paper presents a three-phase, top-down, optimization-based approach for designing an IGCC plant with precombustion $\mathrm{CO}_{2}$ capture in a process simulator environment. In the first design phase, important global design decisions are made on the basis of plant-wide optimization studies with the aim of increasing IGCC thermal efficiency and thereby making better use of coal resources and reducing $\mathrm{CO}_{2}$ emissions. For the design of an IGCC plant with $90 \% \mathrm{CO}_{2}$ capture, the optimal combination of the extent of carbon monoxide (CO) conversion in the water-gas shift (WGS) reactors and the extent of $\mathrm{CO}_{2}$ capture in the SELEXOL process, using dimethylether of polyethylene glycol as the solvent, is determined in the first phase. In the second design phase, the impact of local design decisions is explored considering the optimum values of the decision variables from the first phase as additional constraints. Two decisions are made focusing on the SELEXOL and Claus unit. In the third design phase, the operating conditions are optimized considering the optimum values of the decision variables from the first and second phases as additional constraints. The operational flexibility of the plant must be taken into account before taking final design decisions. Two studies on the operational flexibility of the WGS reactors and one study focusing on the operational flexibility of the sour water stripper (SWS) are presented. 


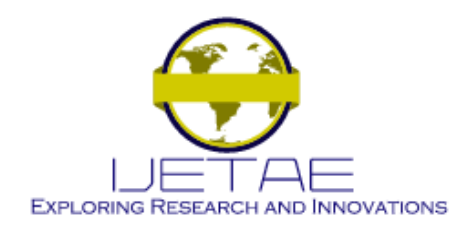

International Journal of Emerging Technology and Advanced Engineering

Website: www.ijetae.com (ISSN 2250-2459, ISO 9001:2008 Certified Journal, Volume 10, Issue 08, August 2020)

At the end of the first iteration, after executing all the phases once, the net plant efficiency (HHV basis) increases to $34.1 \%$ compared to $32.5 \%$ in a previously published study (DOE/NETL-2007/1281; National Energy Technology Laboratory, 2007). The study shows that the three-phase, top-down design approach presented is very useful and effective in a process simulator environment for improving efficiency and flexibility of IGCC power plants with $\mathrm{CO} 2$ capture. In addition, the study identifies a number of key design variables that has strong impact on the efficiency of an IGCC plant with $\mathrm{CO} 2$ capture.

(Botero et. al., 2012) carried out Performance of an IGCC Plant with Carbon Capture and Coal-CO2- Slurry Feed: Impact of Coal Rank, Slurry Loading, and Syngas Cooling Technology. Steady-state process simulation is used in this work to confirm published findings and present a comprehensive assessment of the impact of the coal rank, gasifier cooling technology, and $\mathrm{CO} 2$ slurry loading uncertainty on the performance advantage of $\mathrm{CO}_{2}$ slurryfed plants. A power generation efficiency improvement of up to $25 \%$ (5\%-points) is predicted, which is shown to increase with decreasing coal rank and to be highest for full-quench gasifier cooling technology; the latter is a significant source of capital cost savings and is especially attractive when combined with $\mathrm{CO}_{2}$ slurry feed. Using $\mathrm{CO}_{2}(\mathrm{l})$ instead of water slurry reduces the performance penalty of low-rank coal gasification by half, thus substantially improving the feedstock flexibility of the plant. With a single exception, the performance benefit of coal- $\mathrm{CO}_{2}$ slurry was found to be outside the uncertainty range of the slurry loading, which is still one of the key unknowns of this alternative feed system.

(Siefert et. al., 2016) conducted Comprehensive Exergy Analysis of Three IGCC Power Plant Configurations with $\mathrm{CO}_{2}$ Capture. We have conducted comprehensive exergy analyses of three integrated gasification combined cycle with carbon capture and storage (IGCC-CCS) power plant configurations: (1) a baseline model using Selexol ${ }^{\mathrm{TM}}$ for $\mathrm{H}_{2} \mathrm{~S} / \mathrm{CO}_{2}$ removal; (2) a modified version that adds a $\mathrm{H} 2$ selective membrane before the Selexol ${ }^{\mathrm{TM}}$ acid gas removal system; and (3) a modified baseline version that uses a $\mathrm{CO}_{2}$-selective membrane before the Selexol ${ }^{\mathrm{TM}}$ acid gas removal system. While holding the coal input flow rate and the $\mathrm{CO}_{2}$ captured flow rates constant, it was determined that the H2-selective membrane case had a higher net power output (584 MW) compared to the baseline (564 MW) and compared to the $\mathrm{CO}_{2}$-selective membrane case (550 MW). Interestingly, the $\mathrm{CO}_{2}$-selective membrane case destroyed the least amount of exergy within the power plant (967 MW), compared with the Baseline case (999 MW) and the H2-membrane case (972 MW).
The main problem with the $\mathrm{CO}_{2}$-selective membrane case was the large amount of $\mathrm{H} 2$ (48 MW worth of $\mathrm{H} 2$ chemical exergy) remaining within the supercritical $\mathrm{CO}_{2}$ that exits the power plant. Regardless of the $\mathrm{CO}_{2}$ capture process used, the majority of the exergy destruction occurred in the gasifier (305 MW) and gas turbine $(\sim 380$ MW) subsystems, suggesting that these two areas should be key areas of focus of future improvements.

On the example of the process flowsheet of the IGCC with a power of $500 \mathrm{MW}$, running on Kuznetsk bituminous coal, by means of software Thermoflex, the influence of the developed technical solutions on the efficiency of the power plant is considered (Gordeev et. al., 2017). It is received that rise in steam-air blast temperature to $900^{\circ} \mathrm{C}$ leads to an increase in conversion efficiency up to $84.2 \%$. An increase in temperature levels of fuel gas clean-up to $900 \square \mathrm{C}$ leads to an increase in the IGCC efficiency gross/net by $3.42 \%$. Cycle air heating reduces the need for fuel gas by $40 \%$ and raises the IGCC efficiency gross/net by $0.85-1.22 \%$. The offered solutions for IGCC allow to exceed net efficiency of analogous plants by $1.8-2.3 \%$.

(Huang et. al., 2010) presented Techno-economic assessment of pulverized coal boilers and IGCC power plants with $\mathrm{CO}_{2}$ capture To highlight the pros and cons of both technologies in connection with an integrated $\mathrm{CO}_{2}$ capture, a comparative analysis of ultrasupercritical PC and IGCC is carried out in this paper. The technical design, the mass and energy balance and the system optimizations are implemented by using the ECLIPSE chemical plant simulation software package. Built upon these technologies, the $\mathrm{CO}_{2}$ capture facilities are incorporated within the system. The most appropriate $\mathrm{CO}_{2}$ capture systems for the PC system selected for this work are the oxy-fuel system and the post-combustion scheme using Monoethanolamine solvent scrubber column (MEA). The IGCC systems are designed in two configurations: Water gas shift reactor and Selexol-based separation. Both options generate $\mathrm{CO}_{2}$-rich and hydrogen rich-gas streams. Following the comparative analysis of the technical performance attributes of the above cycles, the economic assessment is carried out using the economic toolbox of ECLIPSE is seamlessly connected to the results of the mass and energy balance as well as the utility usages. The total cost assessment is implemented according to the step count exponential costing method using the dominant factors and/or a combination of parameters. Subsequently, based on a set of assumptions, the net present value estimation is implemented to calculate the breakeven electricity selling prices and the $\mathrm{CO}_{2}$ avoidance cost. 


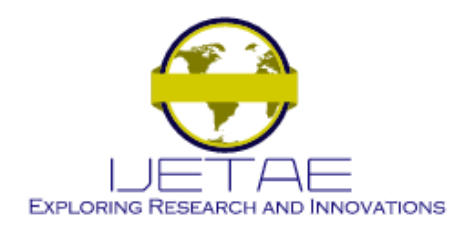

International Journal of Emerging Technology and Advanced Engineering

Website: www.ijetae.com (ISSN 2250-2459, ISO 9001:2008 Certified Journal, Volume 10, Issue 08, August 2020)

(Jiménez et al., 2009) investigated Integrated gasification combined cycle (IGCC) process simulation and optimization. In this paper, a process simulation tool is proposed for simulation of IGCC. This tool is used to improve IGCC's efficiency and the environmental performance through an analysis of the operating conditions, together with process integration studies. Pinch analysis principles and process integration insights are then employed to make topological changes to the flowsheet to improve the energy efficiency and minimize the operation costs. Process data of the Texaco gasifier and the associated plants (coal preparation, air separation unit, gas cleaning, sulfur recovery, gas turbine, steam turbine and the heat recovery steam generator) are considered as a base case, and simulated using Aspen Plus®. The results of parameter analysis and heat integration studies indicate that thermal efficiency of $45 \%$ can be reached, while a significant decrease in $\mathrm{CO}_{2}$ and $\mathrm{SO} x$ emissions is observed. The $\mathrm{CO}_{2}$ and $\mathrm{SO} x$ emission levels reached are 698 $\mathrm{kg} / \mathrm{MWh}$ and $0.15 \mathrm{~kg} / \mathrm{MWh}$, respectively. Application of pinch analysis determines energy targets, and also identifies potential modifications for further improvement to overall energy efficiency. Benefits of energy integration and steam production possibilities can further be quantified. Overall benefits can be translated to minimum operation costs and atmospheric emissions.

(Liang et. al., 2013) carried out Technical and Economic Evaluation of China's Integrated Gasification Combined Cycle: The Case of Yantai Project. This essay analyzes the technical requirements and economic attributes of the Chinese IGCC power plant of $400 \mathrm{MW}$ level in plan. It is both necessary and possible for China to develop IGCC power plant with the technical foundation available. The biggest obstacle facing the development of IGCC is the huge amount of investment and high cost of electric generation. According to the sensitivity analysis, investment is the main element affecting the cost of power generation. Though it is difficult to control investment in the present phase, with restricting elements like technique and facility, smooth operation of the project could still be ensured through government's preferential policies toward IGCC power plant, such as setting price for clean electricity, offering investment subsidies and preferential taxes. The premise for such policies is a determined and consistent development strategy of IGCC technique.

(Zhang et. al., 2015) carried out Economic Evaluation of Flexibility in the Design of IGCC Plants with Integrated Membrane Reactor Modules.
This paper applies a systematic methodological framework to assess the economic value of flexible alternatives in the design and operation of an IGCC-MR plant under the aforementioned sources of uncertainty. The main objective is to demonstrate the potential value enhancements associated with the long-term economic performance of flexible IGCCMR project investments, by managing the uncertainty associated with future environmental regulations and fuel costs. The paper provides an overview of promising design flexibility concepts for IGCC-MR power plants and focuses on operational and constructional systems flexibility. Operational flexibility is realized through temporary plant shutdown with considerations of regulatory and market uncertainties. Constructional flexibility is realized by considering the installation of a Carbon Capture and Storage (CCS) unit at three strategic periods: (1) installation at the initial construction phase, (2) retrofitting at a later stage, and (3) retrofitting at a later stage with preinvestment. Monte Carlo simulations and financial analysis demonstrate that, in the presence of irreducible uncertainty, the most economically advantageous flexibility option is to install CCS in the initial IGCC-MR construction phase.

(Xiao et. al., 2013) carried out Thermodynamic Performance Assessment of IGCC Power Plants with Various Syngas Cleanup Processes. The present work explores how much IGCC can benefit from warm gas clean-up(WGCU)in comparison with conventional cold gas clean-up(CGCU) and what are the respective contributions of dry particulates removal and warm gas desulfurization (WGD) in a plant-wide point of view. Influences of key parameters of WGD on thermodynamic performance of IGCC plant including desulfurization temperature, oxygen concentration in the regeneration stream, and $\mathrm{H} 2 \mathrm{~S}$ removal efficiency are discussed. It is obtained that the net efficiency of IGCC with full WGCU experiences an improvement of 1.77 percentage points compared with IGCC with full CGCU. Of which, dry particulates removal without water scrubber contributes about 1 percentage point. The influence of desulfurization temperature on thermodynamic performance of IGCC with WGD is weak especially when it is higher than about 350, which indicates that more focus should be put on investment cost, technical feasibility and sorbent stability for the selection of optimal operation temperature. Generally, $2 \% \sim 3 \%$ of oxygen concentration in the regeneration stream might be reasonable in a thermodynamic performance point of view. 


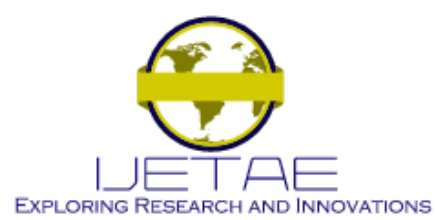

International Journal of Emerging Technology and Advanced Engineering

Website: www.ijetae.com (ISSN 2250-2459, ISO 9001:2008 Certified Journal, Volume 10, Issue 08, August 2020)

In addition, the improvement of 0.31 percentage points can be obtained by removal of $\mathrm{H}_{2} \mathrm{~S}$ in the syngas from 27 ppm to 3 ppm.

(Jinghua et. al., 2020) carried out energy and exergy cooptimization of IGCC with lower emissions based on fuzzy supervisory predictive control. In this work, the authors present an energy and exergy co-optimization method of integrated gasification combined cycle (IGCC) based on Fuzzy Supervisory Predictive Control (FSPC). Firstly, a green IGCC process is proposed which contains three principle couplings: air separation unit (ASU), heat recovery steam steam generator (HRSG) and CO2 capture/storage unit (CCS). Applying the first law of thermodynamics, using substance thermophysical parameters, the energy efficiency and exergy efficiency of IGCC are successively defined. The IGCC power station has features such as closed coupling, large time lag and non-linearity, however, faster response speed and lower overshoot are always the unremitting pursuits. Therefore, the Fuzzy Supervisory Predictive Control (FSPC) method is proposed to implement robust control under complex disturbances by pre-considering unmeasurable disturbance and measurable disturbance. The fuzzy rules extracted from historical bigdata are employed in supervisory layer to make the precise control decision. Finally, the energy and exergy co-optimization model is built and solved for higher efficiency and economic effectiveness. Taking the largescale (3000 MW) IGCC for example, after using FSPC, the efficiency of water recovery is increased from $40.7 \%$ to $62.1 \%$ with the ratio of $52.6 \%$ because of waste heat recovery (WWR) system. The net efficiency of proposed IGCC is increased from $37.6 \%$ to $41.7 \%$ with the ratio of $10.9 \%$. The exergy efficiency of IGCC system is increased from $36.5 \%$ to $39.2 \%$ with the ratio of $7.4 \%$. The proposed method has great has great significance for energy-saving and Near-zero emissions (NZEC) IGCC with high safety and robust control under supercritical (SC) or ultra-super critical (USC) state.

This work seeks to estimate the entropy generation, rate of exergy destruction and exergetic efficiency of integrated gasification combined cycle (IGCC).

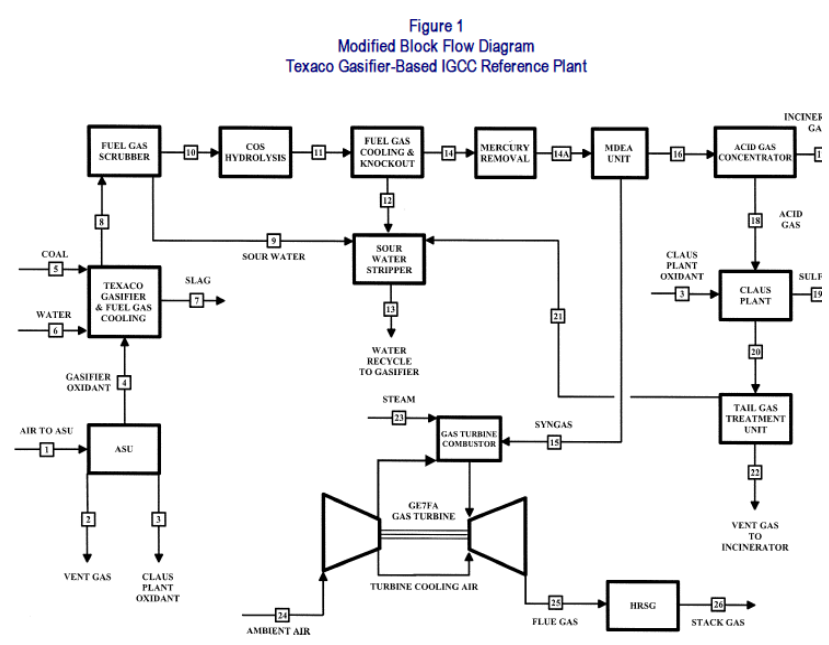

Figure 1: Modified Block Flow Diagram OF Texaco Gasifier-Based IGCC Reference Plant

\subsection{Integrated Gasification Combined Cycle}

The integrated gasification combined cycle (IGCC) produces electricity from a solid or liquid fuel. First, the fuel is converted to syngas. Syngas is a mixture of hydrogen and carbon monoxide. Second, the syngas is converted to electricity in a combined cycle power block consisting of a gas turbine process and a steam turbine process which includes a heat recovery steam generator (HRSG). The combined cycle technology is similar to the technology used in modern natural gas fired power plants. Coal based IGCC plants are not commercialized yet. A number of demonstration plants with electric output up to $300 \mathrm{MW}$ have been built in Europe and the US, all with financial support from government. The motivation for pursuing this technology is the potential for better environmental performance at a low marginal cost. This is especially true for mercury removal and $\mathrm{CO}_{2}$ capture. In order to compete with conventional pulverized coal plants under current environmental regulation, the main challenges facing the IGCC technology today are capital cost and availability (Rao et. al., 2014) 


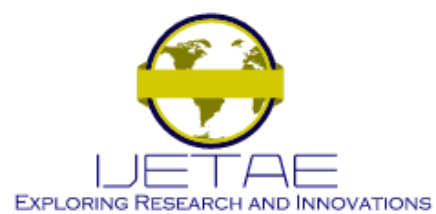

International Journal of Emerging Technology and Advanced Engineering

Website: www.ijetae.com (ISSN 2250-2459, ISO 9001:2008 Certified Journal, Volume 10, Issue 08, August 2020)

\subsubsection{IGCC Process Description}

The IGCC is a power generation system that integrates a gasification process with a combined cycle. Coal (or other hydrocarbon fuel such as petroleum coke, biomass) is converted into syngas through the gasification system. The syngas consists mainly of hydrogen (H2) and carbon monoxide (CO).After cleaning; the syngas is used as fuel in the combine cycle to produce electricity generation. The combined cycle is more efficient than conventional powergenerating systems for it re-using waste heat to produce more electricity. This system consists mainly four parts: air separation unit, gasifier, syngas cooling and cleanup processes, and combined cycle (Jiménez et. al., 2009).

\subsubsection{Advantages of IGCC Technology}

(Rao et. al., 2014) presented advantages of IGCC technology.

a) Higher Fuel Flexibility: IGCC plants can use any high hydrocarbon fuel, such as low and high-sulfur coal, anthracite, and biomass.

b) Higher Efficiency: The electricity generation efficiency of the IGCC process can be higher than $45 \%$ (HHV) withoutCO2 capture. The net efficiency for IGCC in existing plants is around 40-43\% (LHV) and $38-41 \%$ (HHV) without $\mathrm{CO} 2$ capture. With the development of gas turbines, future net efficiency developments should take efficiencies beyond $50 \%$. This is the significant difference between an IGCC and a pulverized coal (PC) power plant.

c) Lower emission:IGCC plant is inherently lower emission of SOx, NOx and particulate matter (PM) than conventional coal based power plants: the desulfurization rate is $99 \%$, nitrogen oxide emission is $15-20 \%$ of that of the conventional power plants, as can be seen from Table II, the sulfur dioxide emission of current coal-based IGCC plant in between 10 and $140 \mathrm{mg} / \mathrm{Nm} 3$ (the Chinese standard is $1200 \mathrm{mg} / \mathrm{Nm} 3$ ). In a coal IGCC plant, the syngas coming out of the gasifier is under high pressure, it does not need to deal with pollutants in a large volume of flue gas. This means the cost of removing pollutants is relatively lower. d) Potential in $\mathrm{CO}_{2}$ sequestration: As mentioned above, the syngas from the gasifier is under high pressure. So $\mathrm{CO}_{2}$ removal IGCC plant requires smaller equipment and simpler process than the conventional coal power station $\mathrm{CO}_{2}$ removal, such as the post-combustion $\mathrm{CO}_{2}$ removal. By incorporating a catalyzed water-gas shift reaction in the process, $\mathrm{CO}_{2}$ can be captured at higher pressure by commercially available technologies, which can be utilized for enhanced oil recovery (EOR) or enhanced coal bed methane recovery (ECMR).

e) Marketable by products: During the gasification and gas clean-up process, mineral material (ashes and other inert species) is transformed into slag as a kind of byproduct, which may commercial value in nearby industries. For example, the slag can be used in construction and building applications.

f) Multiple products for $\mathrm{H} 2$ and Power: The flue gas is essentially hydrogen after $\mathrm{CO}_{2}$ capture, which is gaining popularity as a potential clean-burning fuel source of the future for vehicles and other industries.

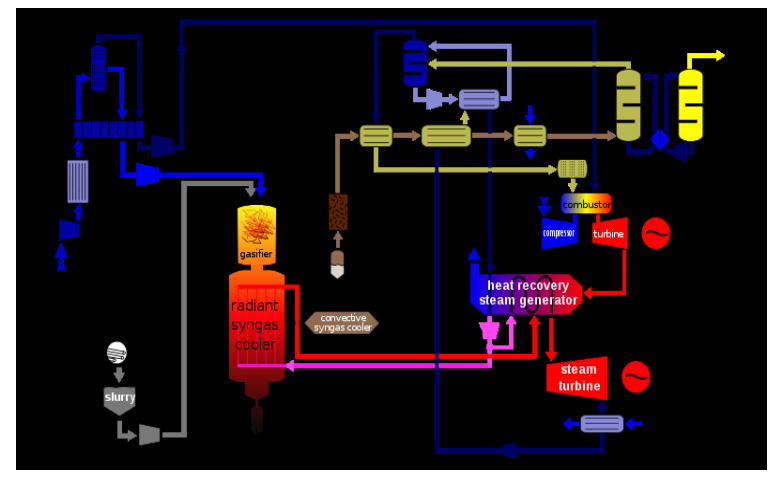

Fig - 2: IGCC Plant block Diagram (Rao et. al.,2014) 


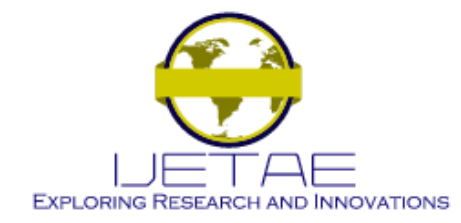

International Journal of Emerging Technology and Advanced Engineering

Website: www.ijetae.com (ISSN 2250-2459, ISO 9001:2008 Certified Journal, Volume 10, Issue 08, August 2020)

Table.1

Main Milestones of IGCC Technology Development (Wang, 2016)

\begin{tabular}{|c|c|}
\hline time & Milestone \\
\hline 1812 & $\begin{array}{l}\text { Foundation of London Gas, Light and Coke Company. } \\
\text { Gasification firstly used as a commercial process to } \\
\text { generate town gas for lighting and cooking. (Higman and } \\
\text { van der Burgt, 2003) }\end{array}$ \\
\hline 1887 & $\begin{array}{l}\text { Lurgi GmbH of Germany was granted the first major } \\
\text { patent in gasification process.(Miller, 2005) }\end{array}$ \\
\hline 1895 & $\begin{array}{l}\text { William Hampson and Carl von Linde independently } \\
\text { filed for patent of the cryogenic cycle used in the air } \\
\text { liquefaction process. Continuous oxidant supply for } \\
\text { gasification became possible.(Higman and van der } \\
\text { Burgt, 2008a) }\end{array}$ \\
\hline 1950 & $\begin{array}{l}\text { Gumz propose the idea of injecting synthesis gas to gas } \\
\text { turbine as fuel to generate electricity.(Higman and van } \\
\text { der Burgt, 2008a) }\end{array}$ \\
\hline $1970 \mathrm{~s}$ & $\begin{array}{l}\text { U.S government started to sponsor studies to test the idea } \\
\text { of using syngas as fuel for gas turbines. The syngas was } \\
\text { produced by coal gasification process. (Higman and van } \\
\text { der Burgt, 2003) }\end{array}$ \\
\hline $1980 \mathrm{~s}$ & $\begin{array}{l}\text { Cool Water Project (96MW) was launched in } 1984 \text { as } \\
\text { part of DOE's clean coal technology program. Texaco } \\
\text { gasifier derived from Texaco heavy oil gasification } \\
\text { technology was used for syngas synthesis while a GE-7E } \\
\text { gas turbine was selected in the combined cycle. (NETL, } \\
\text { 2013) }\end{array}$ \\
\hline 1994 & $\begin{array}{l}\text { The first commercialized IGCC power plant in the } \\
\text { world, Netherlands Buggenum Power Plant (253MW) } \\
\text { began service. A Single dry coal feed Shell gasifier } \\
\text { SCGP unit was used in this project. (Miller, 2005) }\end{array}$ \\
\hline 1996 & $\begin{array}{l}\text { Polk Tampa Power station (250MW) achieved operation. } \\
\text { This station firstly integrated ASU and gas turbine by } \\
\text { injecting nitrogen generated from ASU to gas turbine for } \\
\text { the aim of NOx control.(NETL, 2013) }\end{array}$ \\
\hline 1998 & $\begin{array}{l}\text { One of the largest commercial IGCC projects started } \\
\text { operation in Puertollano, Spain with net capacity of } \\
\text { 330MW. (Higman and van der Burgt, 2008a) }\end{array}$ \\
\hline 2012 & $\begin{array}{l}\text { Huaneng GreenGen started up successfully in Tianjin, } \\
\text { China. With three phases of schedule, } 650 \mathrm{MW} \text { of net } \\
\text { power will make it the world's largest IGCC project and } \\
\text { also the first plant explicitly built } \\
\text { for carbon capture and storage. (NETL, 2013) }\end{array}$ \\
\hline
\end{tabular}

\section{EXERGy Methodology}

The modeling of the IGCC plant was carried out with a presumption: that the plant represents a "block" and includes the main exergy flows that leave the power plant: slag from the gasifier, the exhaust gases from the HRSG outlet, the $\mathrm{CO}_{2}$ stream for the plants with $\mathrm{CCS}$, and a group of different minor outlet streams such as water, $\mathrm{H}_{2} \mathrm{~S}$ in the the precombustion capture plant, vented $\mathrm{N} 2$ from the ASU, etc.

Exergetic analysis has proven to be a reliable tool for identifying, locating, quantifying, qualifying the performance of thermal power plants.

One way to evaluate the efficiency of a process is to analyze the exergy destruction that occurs throughout the whole process. Exergy is defined as the maximum amount of useful work that can be obtained from a material by bringing it into equilibrium with its environment. This makes exergy a property of both the material and its surroundings. Here, the reference environment was taken to be the Earth's atmosphere at standard temperature and pressure, $298 \mathrm{~K}$ and $1 \mathrm{~atm}$, and with the chemical composition listed in Table 2. The further away the material is from equilibrium with the reference environment, the more exergy is associated with the material. By this definition, exergy can only be positive, unless the material is in complete thermal, mechanical, and chemical equilibrium with the reference environment. Since exergy is equal to the theoretical maximum amount of useful work, tracking the exergy destruction is a good indication for which parts or processes within the power plants have the greatest potential to be improved so as to increase net power production. As seen in Table 2, we have assumed for simplicity that the activities of the liquid and solid species are equal to 1 , even though these species do form a mixture in the environment and hence have activities less than 1 . We made this assumption for liquid water because different power plants will have reference water environments with different levels of salinity; and we made this assumption for solids because the largest error in the calculation of the exergy in the coal ash and coal slag is the uncertainty in the exact crystal state of the solids entering and exiting the gasifier. This error is much larger than the error in assuming that the activity of each solid species is equal to one (Siefert et. al., 2016)

Table 2:

Composition of reference environment at $298 \mathrm{~K}$ and $1 \mathrm{~atm}$.

\begin{tabular}{|l|l|l|l|l|l|l|}
\hline $\begin{array}{l}\text { Gas } \\
\text { species }\end{array}$ & Mol \% & $\begin{array}{l}\text { Liqui } \\
\mathrm{d}\end{array}$ & $\begin{array}{l}\text { Mol } \\
\%\end{array}$ & $\begin{array}{l}\text { Activit } \\
\mathrm{y}\end{array}$ & Solid & $\begin{array}{l}\text { Activit } \\
\mathrm{y}\end{array}$ \\
\hline $\mathrm{Ar}$ & 0.00525 & $\mathrm{H} 20$ & $\begin{array}{l}0.509 \\
2\end{array}$ & 1 & Coal & 1 \\
\hline $\mathrm{CH} 4$ & $\begin{array}{l}0.000566 \\
6\end{array}$ & & & & Slag & 1 \\
\hline $\mathrm{CO}$ & 0.2656 & & & & Sulfur & 1 \\
\hline $\mathrm{CO} 2$ & 0.2318 & & & & & \\
\hline $\mathrm{H} 2$ & 0.1473 & & & & & \\
\hline $\mathrm{N} 2$ & 0.2630 & & & & & \\
\hline $\mathrm{O} 2$ & 0.3200 & & & & & \\
\hline $\mathrm{H} 2 \mathrm{~S}$ & & & & & & \\
\hline NH3 & & & & & & \\
\hline SO2 & & & & & & \\
\hline $\mathrm{COS}$ & & & & & & \\
\hline
\end{tabular}




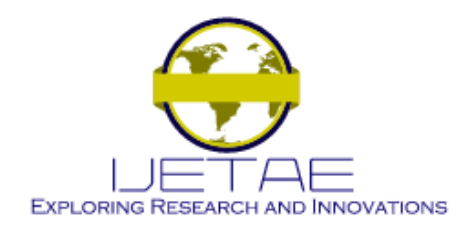

International Journal of Emerging Technology and Advanced Engineering

Website: www.ijetae.com (ISSN 2250-2459, ISO 9001:2008 Certified Journal, Volume 10, Issue 08, August 2020)

\section{1: Exergy Destruction within Each Subsystem}

Different methodology has been adopted by various scholars. The performance analysis of the IGCCMS power plants has been carried out by means of a modular simulation code suitable for studying integrated energy systems, including power plants based on gas turbines, steam turbines, gasification, methanol synthesis, etc. (Carapellucci and Cau, 2001). A high-level exergy analysis of an IGCC-CCS power plant was conducted by (Jinghua et. al., 2020), in which the overall plant was separated into 3 different subsystems or three principle couplings: air separation unit (ASU), heat recovery steam steam generator (HRSG) and CO2 capture/storage unit (CCS). (Gasifier Island, Syngas Treatment, and Combined Cycle.) Here, we break the IGCC-CCS power plant into a total of 26 subsystems within the power plant. These 26 subsystems can be seen in Figures 1, each of which will be discussed in more detail in section 3.0, respectively. All subsystems were assumed to be operating at steady-state conditions. We determined the exergy destruction within each subsystem by taking into account the inlet and outlet streams, the heat entering and leaving, as well as the work being consumed and produced.

Here, again we break the IGCC power plant into a total of 26 subsystems within the power plant. These subsystems can be seen in figure 1. We determined the exergy destruction within each subsystem by taking into account the inlet and outlet streams, the heat entering and leaving, as well as the work being consumed and produced.

The first law of thermodynamics for steady-state control volume for thermal energy transfer to the environment (Siefert et. al., 2016):

$$
\begin{gathered}
\dot{Q}_{\text {env }}=\sum_{i=\text { inlet }} \dot{n}_{i} \hat{h}_{i}-\sum_{o=\text { outlet }} \dot{n}_{0} \hat{h}_{0}-\dot{W} \\
-\sum \dot{Q}_{j}
\end{gathered}
$$

Where $\dot{Q}_{e n v}$ is the thermal energy sent to the environment, $\dot{n}$ stands for the molar flowrate of streams, $\dot{h}$ stands for the molar enthalpy of streams, $W$ is the electrical work leaving the system, and $\dot{Q}_{j}$ stands for the thermal energy transfer out of (+) or into (-) the subsystem from another. The irreversible production of entropy was then calculated using the second law of thermodynamics, taking into account that thermal energy leaves a subsystem at varying temperatures.

Second Law of Thermodynamics for a steady-state control volume with thermal energy leaving at a range of temperatures (Siefert et. al., 2016)

$$
\begin{array}{r}
\dot{\sigma}_{\text {irr }}=\sum_{0=\text { outlet }} \dot{n}_{0} \dot{s}_{0}-\sum_{i=\text { inlet }} \dot{n}_{i} \dot{s}_{i}+\frac{\dot{Q}_{\text {env }}}{T_{\text {env }}} \\
+\sum_{j} \frac{\dot{Q}_{j}}{T_{j, 0}-T_{j, i}} \ln \left(\frac{T_{j, 0}}{T_{j, i}}\right)
\end{array}
$$

Where $\dot{\sigma}_{i r r}$ represents the irreversible entropy production, ^s stands for entropy and $\mathrm{T}$ stands for the temperature of the heat. As shown in the last two terms in Equation (2), heat was separated into two categories: (1) heat leaving to the environment and (2) heat being transferred between two subsystems. We did this in order to differentiate between heat used elsewhere in the plant and heat exiting to the environment, the latter of which was assumed to have zero exergy because it will eventually come into equilibrium with the environment. Heat being transferred between subsystems, however, has a certain amount of exergy associated with it. Equation (3) describes how to calculate the exergy associated with heat transferred between sub-systems.

Exergy in thermal energy transferred between subsystems (Siefert et. al., 2016)

$$
\dot{E}_{j}=\dot{Q}_{j} \cdot\left[1-\frac{T_{e n v}}{T_{j, 0}-T_{j, i}} \ln \left(\frac{T_{j, 0}}{T_{j, i}}\right)\right]
$$

$\dot{E}_{j}$ is the exergy associated with the heat transfer, $T_{j, i}$ is the temperature of the outlet of such a stream. It should be noted that Equation (3) as well as the last term in Equation (2) are only valid when the specific heat capacity of the fluid does not significantly vary along the length of the heat exchanger.

After equation (2) have been used to estimate the irreversible entropy production within the 26 subsystems, the exergy destruction within the 26 subsystems can be calculated using Gouy-Stodola Theorem (Siefert et. al., 2016):

$$
\Phi_{\text {des }}=T_{e n v} \cdot \dot{\sigma}_{\text {irr }}
$$

This theorem states that the rate of exergy destroyed within a subsystem, $F$ des, is equivalent to the product of the temperature of the environment and the entropy generation rate due to irreversible processes, sirr, within the subsystem.

\subsection{Exergy Entering and Exiting Subsystems}

The Exergy Entering and Exiting Subsystems were modeled using (Ghannadzadeh, 2012)

$$
\hat{\boldsymbol{\epsilon}}=\left[\left(\widehat{\boldsymbol{h}}-\widehat{\boldsymbol{h}}_{\text {stp }}\right)-\boldsymbol{T}_{\text {env }}\left(\widehat{\boldsymbol{S}}-\widehat{\boldsymbol{S}}_{\text {stp }}\right)\right]+\boldsymbol{\epsilon}_{\text {chem }}
$$




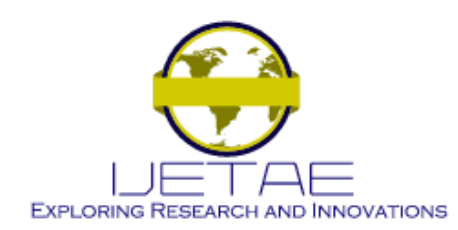

\section{International Journal of Emerging Technology and Advanced Engineering}

Website: www.ijetae.com (ISSN 2250-2459, ISO 9001:2008 Certified Journal, Volume 10, Issue 08, August 2020)

where, $\widehat{\boldsymbol{h}}$ and $\widehat{\boldsymbol{S}}$ represent the molar enthalpy and molar entropy, respectively, of the stream at the temperature and pressure at which they enter/exit a subsystem while the $\widehat{\boldsymbol{h}}_{\boldsymbol{s t p}}$ and $\widehat{\boldsymbol{S}}_{\boldsymbol{s t p}}$ represent the molar enthalpy and molar entropy of the stream if the elements in the stream were at the same temperature and mechanical pressure of the reference environment. $\boldsymbol{\epsilon}_{\text {chem }}$ is the molar chemical exergy, which is related to the Gibbs free energy of a species when brought into full chemical equilibrium with the chemicallystable species in the environment, i.e., $\mathrm{N}_{2}, \mathrm{O}_{2}, \mathrm{H}_{2} \mathrm{O}, \mathrm{CO}_{2}$, $\mathrm{H}_{2} \mathrm{~S}, \mathrm{Ar}, \mathrm{CH}_{4}, \mathrm{COS}, \mathrm{NH}_{3}, \mathrm{CO}, \mathrm{H}_{2}$, Coal, Slag and Sulphur.

$$
\dot{W}=\dot{\boldsymbol{m}}_{\boldsymbol{i}} \boldsymbol{h}_{\boldsymbol{i}}-\dot{\boldsymbol{m}}_{\boldsymbol{j}} \boldsymbol{h}_{j}
$$

Where $W$ is power produced, $m_{i}$ and $\dot{\boldsymbol{m}}_{\boldsymbol{j}}$ are inlet mass flow rate and outlet mass flow rate respectively, $h_{i}$ and $h_{j}$ are the fluid inlet and outlet enthalpies respectively.

\subsection{Exergy Analysis Tool}

(Carlier, 2013) modeled the exergy balance for each system $\mathrm{j}$ of the power plant is given by under statutory conditions and assuming that the changes in kinetic and potential energy are negligible. A system may comprise one or more units of operations defined by a control volume for each of the 26 subsystems, which sets the boundary to which equation 7 is applied:

$$
0=\dot{Q}_{j}\left(1-\frac{T_{0}}{T}\right)-\dot{W}_{j}-\dot{I}_{j}+\sum_{i} \dot{E}_{i, j}
$$

Where $T_{0}$ and $P_{0}$ are the temperature and pressure at ambient conditions. The total exergy flow will is calculated as

$$
\dot{E}_{i, j}=e_{i, j} \dot{m}_{i, j}
$$

The exergy destruction term can be determined when the work $\dot{W}_{j}$ and heat flows $\dot{Q}_{j}$ alongside the specific exergy flow for stream $i$ entering and $j$ exiting the system are known. The exergy flow terms may be calculated with equation 9:

$$
e_{i}=e_{C h}+e_{P h}
$$

Where

$$
e_{P h}=h_{i}-T_{0} s_{i}-\left(h_{0}-T_{0} s_{0}\right)
$$

Where, again, $e_{P h} \quad$ and $e_{C h}$ are physical and chemical exergies, respectively.

\section{RESUlTS AND DISCUSSION}

Here, we present the results from all three models of the power production, the exergy destruction in each subsystem, and the exergy remaining in streams that exit the power plant. Additionally, the thermal energy transferred to the environment and the exergy associated with heat transfer between subsystems are presented. In consonance with the work of (Siefert et. al., 2016), the total exergy in the heat transferred between subsystems sums to zero. As mentioned previously, all heat transfer between subsystems either came from or was transferred to the Steam subsystem. Again, in agreement with (Siefert et. al., 2016), positive values for the exergy in heat mean the heat is leaving that particular subsystem for the Steam Subsystem. In addition to presenting the exergy in units of MW, values were normalized by the total inlet exergy for an easier comparison. The values for the normalized power, the normalized exergy destruction, and the normalized exergy remaining sum to $100.0 \%$ of the total inlet exergy.

The highest exergetic efficiency occurs at 0.96 ; while the lowest occurred at stream 24 with a value of 0.60 . However, this is obtained by a very efficient configuration, based on a dry-feed gasifier, a state-of-the-art gas turbine, an optimized heat recovery: it is representative of the performance obtained by a 'mature' IGCC, rather than by 'demonstration' plants. The loss of efficiency due to precombustion capture is severe: some percentage points are lost due to a number of factors (Lozza et. al., 2009): (i) loss of syngas heating value, due to the exothermic shift reaction (ii) loss of the steam turbine power, caused by the steam extraction needed to achieve the required S/C in the WGS reactors, (iii) the energy consumption (pumps and LP steam) of gas separation plant, (iv) the power requirement of the $\mathrm{CO} 2$ compressor. The highest exergetic efficiency occurs at 0.96; while the lowest occurred at stream 24 with a value of 0.60 . the lower loss of efficiency were encountered in other pre-combustion configurations, but strating from intrinsically lower performance.

Results from total exergy breakdown shows, in consonance with (Pozo et. sl., 2020), the electrical power output, the total exergy destruction of each power plant block, and the exergy flows leaving the plant. The modeling of the IGCC plant was carried out with a presumption: that the plant represents a "block" and includes the main exergy flows that leave the power plant: slag from the gassifier, the exhaust gases from the HRSG outlet, the $\mathrm{CO}_{2}$ stream for the plants with CCS, and a group of different minor outlet streams such as water, $\mathrm{H}_{2} \mathrm{~S}$ in the the precombustion capture plant, vented $\mathrm{N}_{2}$ from the ASU, etc. 


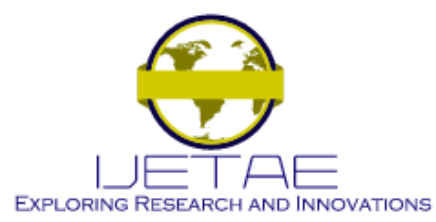

International Journal of Emerging Technology and Advanced Engineering

Website: www.ijetae.com (ISSN 2250-2459, ISO 9001:2008 Certified Journal, Volume 10, Issue 08, August 2020)

From the exergy breakdown, results show that most of the exergy destruction occurs in the gassifier and the combustion chamber of the gas turbine, where the chemical degradation of the fuel takes place. Again, the high-energy utilization of the gassifier, which is greater than $85 \%$, is due to the large amount of incoming exergy to this plant section, although the exergy loss contribution surpasses $30 \%$. The gas turbine presents a low-energy utilization (around 65\%) with a high overall loss contribution (approximately 40\%). With regard to the precombustion $\mathrm{CO} 2$ capture IGCC model, substantial losses are incurred upon by adding the shift reaction step and acid the acid gas removal unit (AGRU), increasing the loss contribution of this block by around $8 \%$ points, and duplicating the exergy losses in this section relative to the unabated IGCC plant. A large portion of the steam is supplied to the WGS unit; therefore, the steam cycle losses are somewhat lower comparatively. Since the precombustion $\mathrm{CO} 2$ capture IGCC plant delivers a pure $\mathrm{CO} 2$ stream at 145 bar, the exergy flow leaving the system is twice the amount of the unabated IGCC model, where the only source of exergy flow leaving the plant are the exhaust gases from the HRSG and to a lesser extent the slag and captured sulfur in the absorption treatment unit.

This work concludes by specifying the highest exergetic destruction and the lowest exergetic destruction. Like all other exergy modeling, the combustion chamber and the HRSG has the highest exergy destruction. The reason has been that in these components of the integrated gasification combined cycle (IGCC) houses the greatest temperature activities.
Table 3:

Inputs to computational model

\begin{tabular}{|l|l|l|l|}
\hline $\begin{array}{l}\text { Stream } \\
\text { number }\end{array}$ & $\begin{array}{l}\text { Mass flow } \\
\text { rate }(\mathrm{kg} / \mathrm{s})\end{array}$ & Pressure $(\mathrm{kPa})$ & $\mathrm{T}(0 \mathrm{C})$ \\
\hline Stream 1 & 0.10534 & $101,356.50$ & 15 \\
\hline Stream 2 & 0.08151 & 137,900 & 15.5556 \\
\hline Stream 3 & 0.3616 & 206,850 & 32.2222 \\
\hline Stream 4 & 0.002346 & $4,481,750$ & 108.3333 \\
\hline Stream 5 & 0 & $101,356.50$ & 15 \\
\hline Stream 6 & 10.8449 & $101,356.50$ & 15 \\
\hline Stream 7 & 0 & 103,425 & 93.3333 \\
\hline Stream 8 & 57.3206 & $2,964,850$ & 232.2222 \\
\hline Stream 9 & 0.3539 & $2,964,850$ & 156.6666 \\
\hline Stream 10 & 56.9667 & $2,861,425$ & 210 \\
\hline Stream 11 & 56.9667 & $2,771,790$ & 210.5556 \\
\hline Stream 12 & 7.0714 & $2,606,310$ & 43.8888 \\
\hline Stream 13 & 10.8449 & $101,356.50$ & 15 \\
\hline Stream 14 & 49.9084 & $2,606,310$ & 39.4444 \\
\hline Stream 15 & 45.003 & $2,499,437.50$ & 154.4444 \\
\hline Stream 16 & 4.7816 & 241,325 & 48.8888 \\
\hline Stream 17 & 2.9764 & 206,850 & 50.5555 \\
\hline Stream 18 & 1.805 & 206,850 & 52.7778 \\
\hline Stream 19 & 0 & 0 & 175 \\
\hline Stream 20 & 1.779 & 162,722 & 126.6666 \\
\hline Stream 21 & 0.3598 & 162,722 & 48.8888 \\
\hline Stream 22 & 1.2116 & $113,767.50$ & 50.5556 \\
\hline Stream 23 & 31.636 & $2,413,250$ & 260 \\
\hline Stream 24 & 405.6784 & $101,356.50$ & 15 \\
\hline Stream 25 & 405.6784 & 102,046 & 610.5556 \\
\hline Stream 26 & 405.6784 & $101,356.50$ & 137.7778 \\
\hline
\end{tabular}




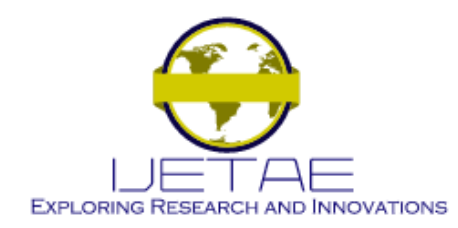

\section{International Journal of Emerging Technology and Advanced Engineering Website: www.ijetae.com (ISSN 2250-2459, ISO 9001:2008 Certified Journal, Volume 10, Issue 08, August 2020)}

\section{CONCLUSIONS}

Exergy analysis is shown in this paper to be able to help understand the performance of coal fired, gas fired combined cycle thermal power plants and identify design possible efficiency improvements. It gives logical solution improving the power production opportunities in thermal power plants. By the exergy analysis we can conclude that main energy loss in boiler in coal based thermal power plant and combustion chamber in gas fired combined cycle thermal power plant. Of course, in every plant component such as a boiler, combustion chamber there is some intrinsic irreversibility which cannot, owing to the present state of technological development, be eliminated. In addition, exergy methods are useful in assessing which improvements are worthwhile, and should be used along with other pertinent information to guide efficiency improvement efforts for steam power plants. Of course, Efficiency of some plant components is improved by increasing their size. (Rao et. al., 2014). This work concludes by specifying the highest exergetic destruction and the lowest exergetic destruction. Like all other exergy modeling, the combustion chamber and the HRSG has the highest exergy destruction.

Results from total exergy breakdown shows, in consonance with (Pozo et. sl., 2020), the electrical power output, the total exergy destruction of each power plant block, and the exergy flows leaving the plant. The modeling of the IGCC plant was carried out with a presumption: that the plant represents a "block" and includes the main exergy flows that leave the power plant: slag from the gassifier, the exhaust gases from the HRSG outlet, the $\mathrm{CO}_{2}$ stream for the plants with CCS, and a group of different minor outlet streams such as water, $\mathrm{H}_{2} \mathrm{~S}$ in the the precombustion capture plant, vented $\mathrm{N}_{2}$ from the ASU, etc.

\section{REFERENCES}

[1] Ali Ghannadzadeh,(2012), exergetic balances and analysis in a process simulator : a way to enhance process energy integration, Doctorial thesis, Universite de Toulouse.

[2] Carapellucci, R. and Cau, G. Un sistema di simulazione modulare per la valutazione delle prestazioni dei sistemi energetici. In Proceedings of the VI National Congress Gruppi Combinati: Prospettive Tecniche ed Economiche, Genoa, Italy, 12-13 November 1992, pp. 63-82.

[3] César Nieto, Erika Arenas, Andrés Arrieta, Zulamita Zapata, Carlos Londoño, Carlos Valdés \& Farid Chejne (2008), Simulation Of Igcc Technologies: Influence Of Operational Conditions (Environmental And Fuel Gas Production), Revista Energética Número 40, Diciembre de 2008, pp. 39-52.
[4] Cristina Botero, Randall P. Field, Robert D. Brasington, Howard J. Herzog, and Ahmed F. Ghoniem, Performance of an IGCC Plant with Carbon Capture and Coal-CO2-Slurry Feed: Impact of Coal Rank, Slurry Loading, and Syngas Cooling Technology, dx.doi.org/10.1021/ie3018093 | Ind. Eng. Chem. Res. XXXX, XXX, $\mathrm{XXX}-\mathrm{XXX}$

[5] Dapeng Liang, Xinpeng Xing, Weidong Shen, Technical and Economic Evaluation of China's Integrated Gasification Combined Cycle: The Case of Yantai Project, Low Carbon Economy, 2013, 4, 117-124 http://dx.doi.org/10.4236/lce.2013.43012.

[6] Debangsu Bhattacharyya, Richard Turton, and Stephen E. Zitney, Steady-State Simulation and Optimization of an Integrated Gasification Combined Cycle Power Plant with CO2 Capture, Ind. Eng. Chem. Res. 2011, 50, 1674-1690, 10.1021/ie101502d

[7] Di Huang, Huisheng Zhang, Shilie Weng and Ming Su, Modeling and Simulation of IGCC Considering Pressure and Flow Distribution of Gasifier, Appl. Sci. 2016, 6, 292; doi:10.3390/app6100292, pp. 112

[8] Ehsan AMIRABEDIN, Mustafa Zeki YILMAZO־GLU, , Senol BAS,KAYA, Exergetic evaluation of an integrated gasification combined cycle power plant simulated by seven different types of Turkish lignite, Turkish J Eng Env Sci (2013) 37: 42 - 55, doi:10.3906/muh-1109-9

[9] G. Lozza, M. Romano and A. Giuffrida, Thermodynamic Performance of IGCC with Oxy-Combustion CO2 capture, $1^{\text {st }}$ international conference on sustainable Fossil Fuels for Future Energy - S4FE 2009

[10] Jiménez, L., et al. Integrated gasification combined cycle (IGCC) process simulation and optimization.

[11] Computers and Chemical Engineering (2009), doi:10.1016/j.compchemeng.2009.04.007

[12] Juzheng Zhang, Michel-Alexandre Cardin, Nikolaos Kazantzis,Simon K. K. Ng, and Y. H. Ma, Economic Evaluation of Flexibility in the Design of IGCC Plants with Integrated Membrane Reactor Modules, Systems Engineering, Syst Eng 18: 208-227, 2015, DOI 10.1002/sys

[13] Nicholas S. Siefert , Sarah Narburgh and Yang Chen, Comprehensive Exergy Analysis of Three IGCC Power Plant Configurations with CO2 Capture, Energies 2016, 9, 669; doi:10.3390/en9090669.

[14] R Carapellucci, G Cau and D Cocco, Performance of integrated gasification combined cycle power plants integrated with methanol synthesis processes, Proc Instn Mech Engrs Vol 215 Part A, pp. 347356

[15] S I Gordeev, T F Bogatova, A F Ryzhkov, Thermodynamic analysis of engineering solutions aimed at raising the efficiency of integrated gasification combined cycle, IOP Conf. Series: Journal of Physics: $\begin{array}{llllll}\text { Conf. Series } 891 & \text { (2017) } 012194 \text { doi } 10.1088 / 1742-\end{array}$ 6596/891/1/012194

[16] Wang M., Pahija E., Liu G., Hui C.-W., 2015, Simultaneous integration and optimization of an igcc plant, Chemical Engineering Transactions, 45, 1891-1896 DOI:10.3303/CET1545316

[17] Y. Huang , S. Rezvani, D. Mcilveen-Wright, N. Hewitt, A. Minchener, J. Mondol, Techno-economic assessment of pulverized coal boilers and IGCC power plants with $\mathrm{CO} 2$ capture, Front. Chem. Eng. China 2010, 4(2): 196-206 DOI 10.1007/s11705-009-0237-y 


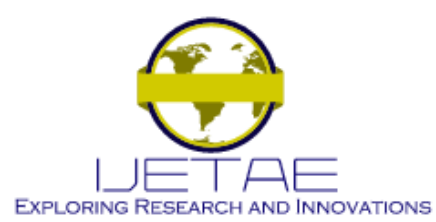

International Journal of Emerging Technology and Advanced Engineering Website: www.ijetae.com (ISSN 2250-2459, ISO 9001:2008 Certified Journal, Volume 10, Issue 08, August 2020)

[18] Yue Wang, 2016, Modelling and Simulation Study of IGCC Power Plant with Activated Carbon-based arbon Capture Process, Thesis Submitted to the University of Warwick for the degree of Doctor of Philosophy, School of Engineering,

[19] Yunhan Xiao, Zhen Li, Bo Wang, Lifeng Zhao and Jinling Chi, Thermodynamic Performance Assessment of IGCC Power Plants with Various Syngas Cleanup Processes, Journal of Thermal Science Vol.21, No.5 (2012) 391-403, DOI: 10.1007/s11630-012-0560-3
[20] Carlos Arnaiz del Pozo, Angel Jimenze Alvero, Jan Hendrik Cloete, Schalk Cloete and Schahriar Amini, Exergy Analysis of Gas Switching Chemical Looping IGCC Plants, Energies 2020, 13, 544; doi: 10.3390/en13030544.

[21] Carlier, R. N. Termodinamica; Dextra: San Diego, CA, USA, 2013 